\title{
The impact of different forms of cognitive scarcity on online privacy disclosure
}

\begin{abstract}
The way in which people manage information disclosure contributes to one of the biggest challenges of the information age - online privacy. The current study sheds a light on the privacy paradox, a gap between attitudes and behaviour, by exploring the role of cognitive scarcity in privacy disclosure behaviour. Using a large sample of the UK online general population $(\mathrm{N}=969)$, we conducted a Randomised Controlled Trial experiment to test the effect of two forms of induced cognitive scarcity: ego depletion and working memory load, on information disclosure levels. Results indicate a significant effect of both forms of scarcity on information disclosure in the direction of increasing the latter, even in the context of a generalised high disclosure. Findings are discussed in light of the privacy paradox, future research, possible remedies and interventions.
\end{abstract}

Keywords: Cognitive scarcity, information disclosure, working memory, ego depletion, privacy 


\section{Introduction}

Some of the biggest challenges of the information age pertain to the collection, use and ownership of information. Yet, the increasing rate at which data is accumulating far outweighs the growth of knowledge about people's behaviour regarding personal data. One particular problem of interest to psychologists and behavioural scientists has been termed 'the privacy paradox'; the observation that people express greater concern in their attitudes about privacy than they reveal in their actual behaviour. The existence of this gap can be partly explained by the highly context-dependent nature of individuals' behaviour, especially in online settings. Lack of certainty and knowledge about the way in which personal information is collected, stored, as well as used and potentially misused, are the sources of this vulnerability. 
The privacy paradox suggests that policies are insufficient if they merely provide better information in order to change the knowledge and attitudes of individuals who are assumed to be self-regulating. Understanding people's behaviour with respect to information privacy is crucial for the design of effective policies that provide protection for citizens and consumers. The large majority of studies on privacy-related behaviour are regarding people's attitudes towards different contexts of information sharing and kinds of information people are willing to disclose. Westin (1991) created the General Privacy Concern Index, the earliest attitudinal segmentation regarding privacy concerns. In this study, American respondents were divided into three groups based on their answers to four questions. About $25 \%$ of the sample were classified as privacy fundamentalists who exhibit high levels of distrust towards organisations asking for their information, worry about the way in which their information is used and favour government regulation on privacy. The majority (57\%) of respondents fell into the category labelled privacy pragmatists, people who weigh the costs and benefits of information disclosure and privacy, think of rules and regulations in practical terms and would like to be given choices about the way information is used. Finally, the unconcerned, representing $18 \%$ of the sample, are generally trustful of organisations collecting their personal information, comfortable with existing procedures and willing to give away their information if it benefits them as consumers. With respect to specific domains, levels of concern depend on the type of information in question. Early research with Internet users found that more than $80 \%$ were somewhat or very concerned about online threats to their personal privacy (Westin, 1998; Cranor, Reagle \& Ackerman, 1999). Privacy concerns vary across situations. They are generally higher with regard to sensitive information about credit cards or personal health, and relatively low for consumption related information (Cranor et al., 1999). In addition, levels of concern also vary across entities, such as e-commerce sites, depending on their perceived trustworthiness (Belanger, Hiller \& Smith, 2002) and the relevance or legitimacy of the information collected (Spiekermann, Grossklags \& Berendt, 2001). 


\subsection{Moderators and Mediators}

Based on an extensive review of the literature, Smith et al. (2011) have proposed an Antecedents Privacy Concerns - Outcomes (APCO) model of information privacy behaviour. The model identifies privacy awareness and experiences, personality and demographic differences, as well as cultural background as antecedents of privacy concerns (and potential moderators of privacy behaviours). These privacy concerns, in conjunction with contextual factors, influence actual behaviour, such as information disclosure. Two frequently studied dimensions that, along with privacy concern, are thought to affect behaviour are trust and the privacy calculus. Trust has been shown to moderate the effect of privacy concerns on information disclosure (Bansal, Zahedi \& Gefen, 2008). The privacy calculus consists of evaluations of the trade-off between costs, including risks, and benefits. In relation to risk, a key variable that affects privacy behaviour is perceived control over one's personal information. Research has shown that greater perceived control is associated with lower level privacy concern (Xu, 2007). However, individuals who feel more in control over their personal information may be more likely to release sensitive information even in the face of high levels of risk (Brandimarte, Acquisti \& Loewenstein, 2013). An illusion of control bias can make people unable to differentiate between publication control and control of access to personal information. Indeed, there is a clear relationship between perceived control and trust (Olivero \& Lunt, 2004), which information-collecting entities often use to their advantage (Acquisti et al., 2015). Contena et al. (2015) have further polished a comprehensive instrument developed by Krasnova et al (2012) combining several of the dimensions associated with information privacy including privacy concerns, perceived risks and benefits, trust and perceived control.

\subsection{The Privacy Paradox}


While privacy concerns remain an important part of the empirical evidence that can inform public policies, the limitations of focusing on privacy attitudes have become evident. An early study that investigated the gap between privacy attitudes and behaviour was conducted in the context of ecommerce (Spiekermann et al., 2001). Self-reported preferences about information privacy (using Westin, 1991 approach) were compared to an online shopping task that required actual disclosing behaviour to an anthropomorphic 3-D shopping bot. Results indicated a strong tendency for individuals to disclose personal information across different segments of privacy attitudes. Norberg and colleagues (2007) studied intentions to disclose in relation to actual disclosure of 17 items of personal information. Their research not only found a gap between intentions to disclose and actual levels of disclosure, which they termed 'privacy paradox', but that this gap was unaffected by levels of trustworthiness of the information recipient (e.g., a bank vs pharmaceutical company). Finally, a field experiment that advertised an online survey as a marketing study for a credit card company asked participants to disclose various items of personal data (Malheiros, Preibusch \& Sasse, 2013). While individuals high on the trait of reciprocity disclosed a significantly higher number of personal items, privacy concerns measured by Westin (1991) segments had no such effect.

Alternative, more indirect, behavioural measures have worked with revealed preferences of information privacy by asking individuals about their willingness-to-pay (WTP) for privacy and willingness-to-accept (WTA) for personal information (see Acquisti, John \& Loewenstein, 2013, for a review). For example, Rose (2005) found that only 47 per cent of survey respondents were willing to pay any amount to protect the privacy of their personal information, although most respondents expressed a concern about their privacy. Findings about people's WTA for personal information are also consistent with a privacy paradox, often indicating a relatively low value attached to privacy. Spiekermann et al. (2001), for instance, reported that even individuals with high levels of privacy concerns revealed personal information in exchange for small discounts. 
In the social web age, the privacy paradox has also been identified in relation to social networking sites, where users can choose to share personal information ranging from birth dates to photographs (Barnes, 2006, Tufekci, 2008). One key study in this area found that disclosure of most types of information was unaffected by general privacy concerns, or a fear of the profile being seen by unwanted audiences (Tufekci, 2008). Over time, the privacy value-action gap appears to have decreased in the social networking domain due to increasing privacy-seeking behaviour, vis-a-vis the public. However, the sharing of information within users' private network has increased (Stutzman, Gross \& Acquisti, 2012). As a result of this increase, along with users' relatively low concern for institutional privacy, compared to social privacy (Young \& Quan-Haase, 2013), sharing with and vulnerability to 'silent' third-party listeners also increased. In addition, users remain susceptible to the choice architecture implemented by commercial interests, such as the default settings for profile visibility on Facebook. 
Different explanations to explain the privacy value-action gap have been proposed (Acquisti, Brandimarte \& Loewenstein, 2015). One position holds that the gap is not a paradox at all: attitudes are global or ideal evaluations or preferences, so it is no surprise that specific instances of behaviour with different cost-benefit trade-offs tend to deviate from those attitudes. Another explanation points to lack of knowledge and uncertainty, indicating that people are strongly influenced by contexts in which decisions are made. The most frequently cited contexts in research on information privacy (Smith, Dinev \& Xu, 2011) include the type of information collected from individuals (e.g. medical, consumer), the sector of information use (e.g. marketing, finance), political context (e.g. law enforcement, public data, media) and technological applications (e.g. e-commerce, online social networks, online profiling). Other contextual variables are based mainly on the assumption that individuals are uncertain about their information privacy preferences, implying that their behaviour is susceptible to heuristic cues and biases (Acquisti et al., 2015). This includes contextual influences commonly associated with behavioural economics, such as framing (Tversky \& Kahneman, 1974), perceived social norms (Cialdini, 2008), emotional states (Loewenstein, O'Donoghue \& Rabin, 2003) and defaults (Johnson \& Goldstein, 2003). 
A study on framing effects investigated information disclosure when privacy notices were framed as either increasing or decreasing in protection (Adjerid, Acquisti, Brandimarte \& Loewenstein, 2013). Results showed that individuals' level of disclosure was less affected by absolute levels of protection than relative levels indicated by the difference between a new level of protection and the level that preceded it. Research also suggests that website designs can serve as powerful frames that affect user trust (Lowry, Wilson \& Haig, 2014; John, Acquisti \& Loewenstein, 2011) and that consumers are willing to pay a premium to purchase from websites with high privacy ratings (Tsai et al., 2011). Similarly, privacy seals can increase levels of trust (Rifon, LaRose \& Choi, 2005), but research has produced mixed results with respect to the effects of seals on actual information disclosure (see Knijnenburg \& Kobsa, 2013, for a discussion). While government regulation serves as a cue that may reduce people's privacy risk perception (Xu, Teo, Tan \& Agarwal, 2010), the mere existence of a company privacy policy may also be wrongly interpreted as an assurance of privacy (Acquisti et al., 2015; Hoofnagle \& Urban, 2014).

Other factors that influence people's disclosure behaviour include social cues, including perceived social norms (Cialdini, 2008). 'Social navigation' cues (information about others' online behaviour) can help users make privacy decisions (Besmer, Watson \& Lipford, 2010; Patil, Page \& Kobsa, 2011). When online survey respondents are told that previous respondents divulged sensitive information, they are also more likely to disclose sensitive information (Acquisti, John \& Loewenstein, 2012). Theories and research on inter-temporal choice indicate that humans tend to be present-biased and thus often seek instant gratification, a problem that is magnified by certain emotional states (Loewenstein et al., 2003). Emotions also influence online information disclosure (Wang, Komanduri, Leon, Norcie, Aquisti \& Cranor, 2011) and a general bias toward immediate gratification or reward seeking may provide another important explanation for the privacy paradox (Acquisti, 2004; Park, Campbell \& Kwak, 2012).

\section{Cognitive scarcity and privacy's disclosure}


While there is a substantial amount of attitudinal studies about privacy, there is an increasing attention to the antecedents of privacy concerns and behaviour, as discussed above. We argue that one of the antecedents of privacy disclosure behaviour are an individual's cognitive functions or, rather, cognitive scarcities.

Impulsive behaviour is more likely when mental resources are diminished (Mullainathan \& Shafir, 2013). This occurs when self-regulation is impaired after previous exertion of self-control

(Baumeister, Sparks, Stillman \& Vohs, 2008) or when the ability to think reflectively is reduced due to cognitive load, distraction or time pressure (Samson \& Voyer, 2012, 2014). After all, individuals are often required to make decisions about their privacy in a highly loaded context in which their cognitive resources are divided among many different tasks (Samson \& Kostyszyn 2015).

Cognitive load in this context is often associated with increased load for people's working memory. Working memory may be defined as the system for the temporary maintenance and manipulation of information, necessary for the performance of such complex cognitive activities as comprehension, learning, and reasoning (Baddeley, 1992). In human-computer interaction (HCI) research, as explored in many previous studies, the issue of cognitive load has been discussed mainly through the lenses of cognitive load theory (Ayres \& Gog, 2009; Hollender, Hofmann, Deneke \& Schmitz, 2010). 
The second form of cognitive scarcity that is directly related to self-regulation is ego depletion. Research in self-regulation that makes use of capacity-based approaches considers self-regulation as a limited commodity that restricts self-regulatory capability (Baumeister \& Heatherton, 1996; Fishbach, Friedman \& Kruglanski, 2003). This approach culminated in the elaboration of the strength model of self-control. According to this model, engaging in acts of self-control draws from a limited 'reservoir' of self-control that, once depleted, results in a reduced capacity for subsequent self-regulation. Baumeister and colleagues termed the state of diminished self-control 'strength' ego depletion (Baumeister, Bratslavsky, Muraven \& Tice, 1998; Baumeister \& Heatherton, 1996; Baumeister, Vohs \& Tice, 2007; Muraven \& Baumeister, 2000). A large amount of research has been conducted on this topic and several moderators (skills, fatigue, motivation, self-efficacy, glucose levels, etc.) of ego depletion explored (see Hagger et al., 2010, for a meta-review).

Given the demonstrated effects of cognitive scarcities on individual's behaviour, our study contributes to understanding of the antecedents of privacy behaviour by raising an important empirical question: What is the impact of cognitive scarcities on the privacy disclosure behaviour? We induce different forms of cognitive scarcity in terms of reduced working memory and ego depletion and measure their impact on the level of information disclosure of participants. Ultimately, we explore which form of cognitive scarcity - ego depletion or reduced working memory - has the most impact. 
Another important moderator that was measurable in our context was affect. Another important moderator that was measurable in our context was affect. Immediate emotions or affective states were shown to influence decisions directly or change individual's perceptions and controlling decision-making processes (Loewenstein \& Lerner, 2003). Previous research has showed that more concerned or anxious individuals are more likely to elicit a behavioral response to a threatening environment or stimulus (MacLeod \& Mathews, 1988) with strategic decisions taken under additional cognitive load being governed to a greater extent by the affective system (Schulz, Fischbacher, Thöni \& Utikal, 2014; Park, Campbell \& Kwak, 2012). Considering privacy disclosure domain, immediate affective states were shown to not only interact with information disclosure by also influence privacy assessment (Li, Sarathy \& Xu, 2011; Kehr, Kowatsch, Wentzel \& Fleisch, 2015). Lerner \& Keltner (2001) further accentuate the role of fear and anger in risk assessments through appraisal-tendency framework that links emotion-specific appraisal processes to several judgments and choice outcomes. Therefore, in our research we control for both positive and negative affect states.

Both positive and negative affect have an impact on ego-depletion. In the case of positive affect, this is because regulating affect requires individuals to overcome an innate tendency to display emotions in response to environmental stimuli (Fishback \& Labroo, 2007). In terms of negative affect, tasks that require self-control are demanding and frustrating and may induce a negative affective state (Hagger et al, 2010; Folkman \& Moskowitz, 2000; Mayer \& Gaschke, 1988). In our study, we control for the positive and negative affects induced by the manipulation of cognitive scarcity. Individuals' affect was measured using Positive and Negative Affect Schedule (PANAS) developed by Crawford \& Henry (2004) and Self-Assessment Manikin (SAM) by Bradely \& Lang (1994). 


\section{Materials and methods}

\subsection{Participants}

A total sample of 969 participants were recruited from the specialised UK panel provider and took part in the online experiment to evaluate the impact of selective attention deficit and cognitive load (ego depletion) on the privacy disclosure level. Online panellists received an invitation to participate in the experiment, along with a link to the online experiment. Of the total sample, $50 \%$ were males while the mean age of the participants reached 50.16 years $(\mathrm{SD}=12.97)$, excluding two participants who did not indicate their age. $41 \%$ and $28 \%$ of participants indicated having graduate or college degrees, respectively. Details of the socio-demographic data are further elaborated in the Appendix tables 1 and 2. Participants were rewarded for their participation by obtaining points that can be later exchanged for actual goods or money.

\subsection{Measures}

Privacy Disclosure. Privacy disclosure level across all the experimental conditions was measured using a 30-item self-disclosure questionnaire developed by Joinson \& Reips (2008). The questionnaire was split equally into two web pages and included 24 sensitive and 6 non-sensitive items (e.g. "Are you left or right handed?" or "Do you carry a donor card?" etc.) with non-sensitive items present on both pages. Overall, the design of the self-disclosure questionnaire replicated Joinson \& Reips' (2008) settings. 
Items related to sensitive personal information, similarly to Joinson \& Reips (2008), were also combined into a sensitivity indicator. This combined indicator was used to assess the impact of cognitive and ego manipulations on individuals' privacy disclosure levels. For sensitive items, the use of 'I prefer not to say' was scored as ' 0 ' and a response to the item scored as ' 1 '. The nonsensitive items, such as “Do you carry a donor card?", “Are you a religious person?”, “Do you give to charity?”, “Are you left or right-handed?", “Which season were you born in?”, and "What is your height?" were included into a combined indicator of non-sensitivity following the same procedure that was used to create a combined indicator of sensitivity.

It is important to note that two questions on weight and height were excluded from combined indicators of sensitive and non-sensitive items, respectively. Though participants were instructed to provide information about their weight and height in kilograms and centimetres, respectively, using open text box types of question, values provided by participants seem to contain variations across centimetres and meters, metric and imperial measurement systems, thus making it problematic for inclusion into analysis. While height is a non-sensitive item (Joinson \& Reips, 2008), weight belongs to the sensitive type of information. Despite exclusion of the question directly asking to disclose the weight, an alternative measure ("Please rate your body weight on the following scale [1 Very underweight, 2, 3, 4, 5 Very overweight]") was included into the combined indicator of sensitivity.

The resulting non-disclosure levels were higher for sensitive items $($ Mean $=0.9512, \mathrm{SD}=0.14)$ compared to the non-sensitive items (Mean $=0.9495, \mathrm{SD}=0.13$, paired $t(969)=7.24, p<0.001)$. Spatial distribution of non-disclosure levels across the sample, using a combined indicator of sensitivity, is presented in Figure 2.

The combined 23-item indicator of sensitivity scored high on interim correlation among all the items (Cronbach's $\alpha=0.94$ ), as well as maintaining an overall reliability score of $\alpha=0.94$ when any of the items were dropped (See Appendix, table 5). Demonstrated reliability of the compound sensitivity indicator supports its use as a dependent variable of privacy disclosure. 


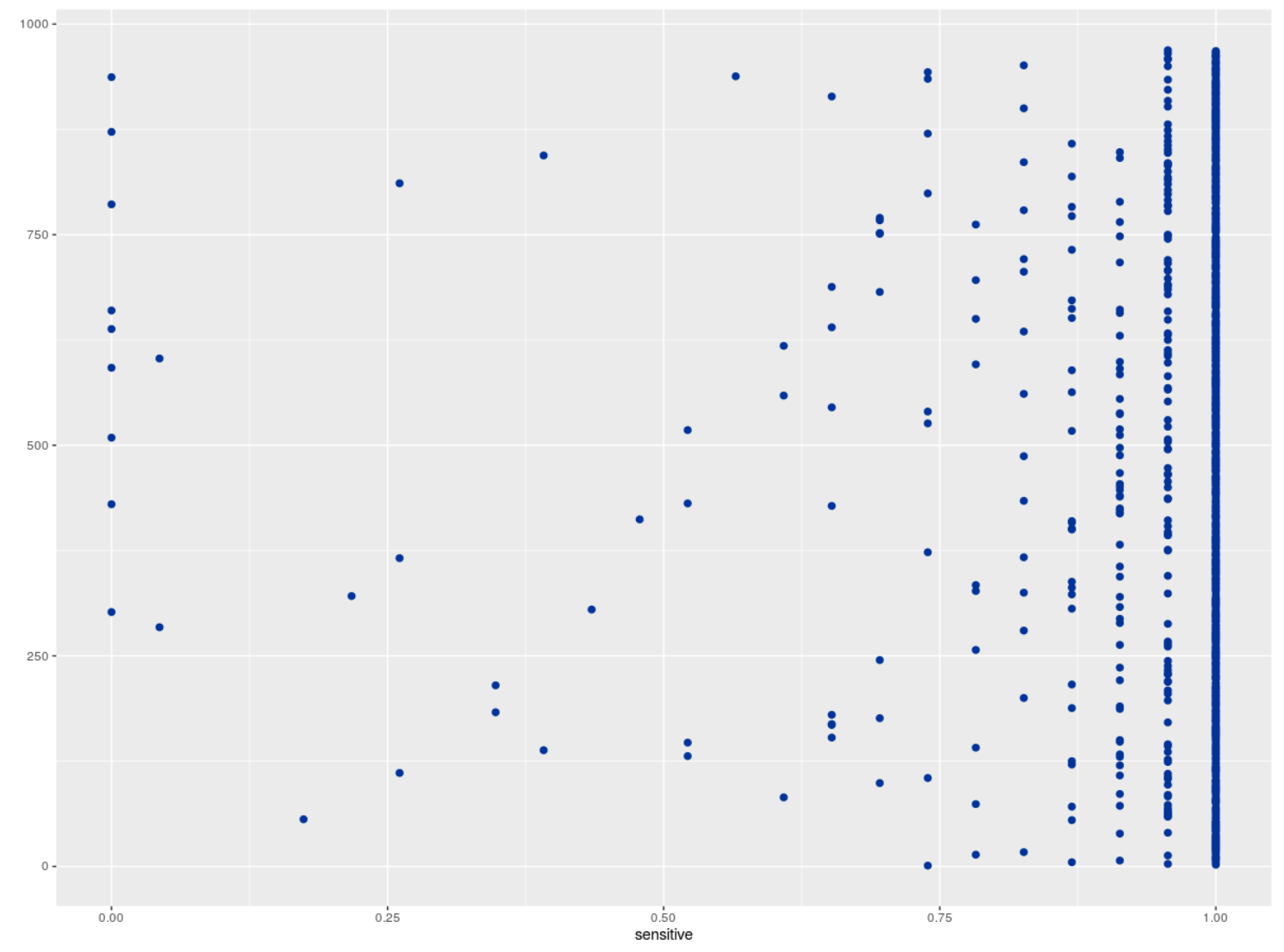

Figure 2. Distribution of information disclosure scores across the participants 
Measures of affect. To control for different levels of emotional responses, we assessed two types of emotional reactions. The Self Assessment Manikin (SAM), initially developed by Bradely \& Lang (1994), was used to assess primary emotions or 'gut feelings' that are the immediate response to a stimulus or an event (Damasio, 1994). We also assessed secondary emotions that are considered to follow the primary response and to be the outcome of a retrospective cognitive appraisal using the Positive and Negative Affect Schedule (PANAS) developed by Crawford \& Henry (2004). Therefore, our analysis includes both types of variables (elicited in the following order): the Positive and Negative Affect Schedule and the Self Assessment Manikin. PANAS (Crawford \& Henry, 2004) schedule, consisting of 20 items of positive and negative affect measures, was placed in a random order. PANAS items were recorded using a 5-point Likert-scale from 1 "Not at all" to 5 "Extremely". Descriptive statistics for this scale and other variables used in the analysis are presented in the Appendix, table 3. The SAM scale was originally developed by Bradely \& Lang (1994) and later refined by many other researchers. In our study, to control for general emotional response, we used the scale to ask respondents to indicate (a) the valence of the emotion (positive or negative) and (b) the level of arousal (intensity of the emotion) they experience at that moment. Both valence and arousal were measured using a 9-point scale, as depicted in the Appendix, Figure 2.

Overall, evaluation of emotional effects of pictures received considerable attention in the prior research (Bradley et al., 2001; Calvo et al., 2004; Ordonana et al., 2009) where emotional effects of images from the International Affective Picture System (IAPS) (containing both Mild and Strong images) were assessed by both PANAS and SAM. Ordonana et al. (2009) demonstrated a very high correspondence between the judgements of emotions reported using SAM, PANAS, and physiological measures of emotions, such as skin-conductance, eye-blinks, facial corrugator muscles and other measures. The reliability of the PANAS positive and negative sub-scales was estimated using Cronbach's $\alpha$ similarly to combined indicator of sensitivity. Cronbach's $\alpha$ was 0.92 for positive scale and 0.95 for negative scale (see tables $4 \& 5$ in the Appendix). 
Another important moderator is age of the respondent: the role of age as control variable is due to the cognitive nature of the task at hand. Age of respondents is considered as a co-variate giving the effect of age on cognitive performance and particularly on memory-related tasks (e.g. Oshea et al, 2016).

\subsection{Design}

The study was conducted in the form of a randomised controlled trial (RCT) experiment using a specialised online experimental platform developed by Expilab (http://expilab.com). Subsequent to giving consent and reading instructions, participants completed a set of socio-demographic questions and were randomly assigned to 3 conditions including ego depletion, reduced working memory and control and proceeded to a short trial stage to familiarize with the task. After completing ego depletion and working memory reducing tasks, excluding those in the control group, participants completed 30-item self-disclosure questionnaire developed by Joinson \& Reips (2008). Ultimately, participants completed self-reported PANAS and SAM scales. Figure 1 outlines the flow of the experiment.

Start

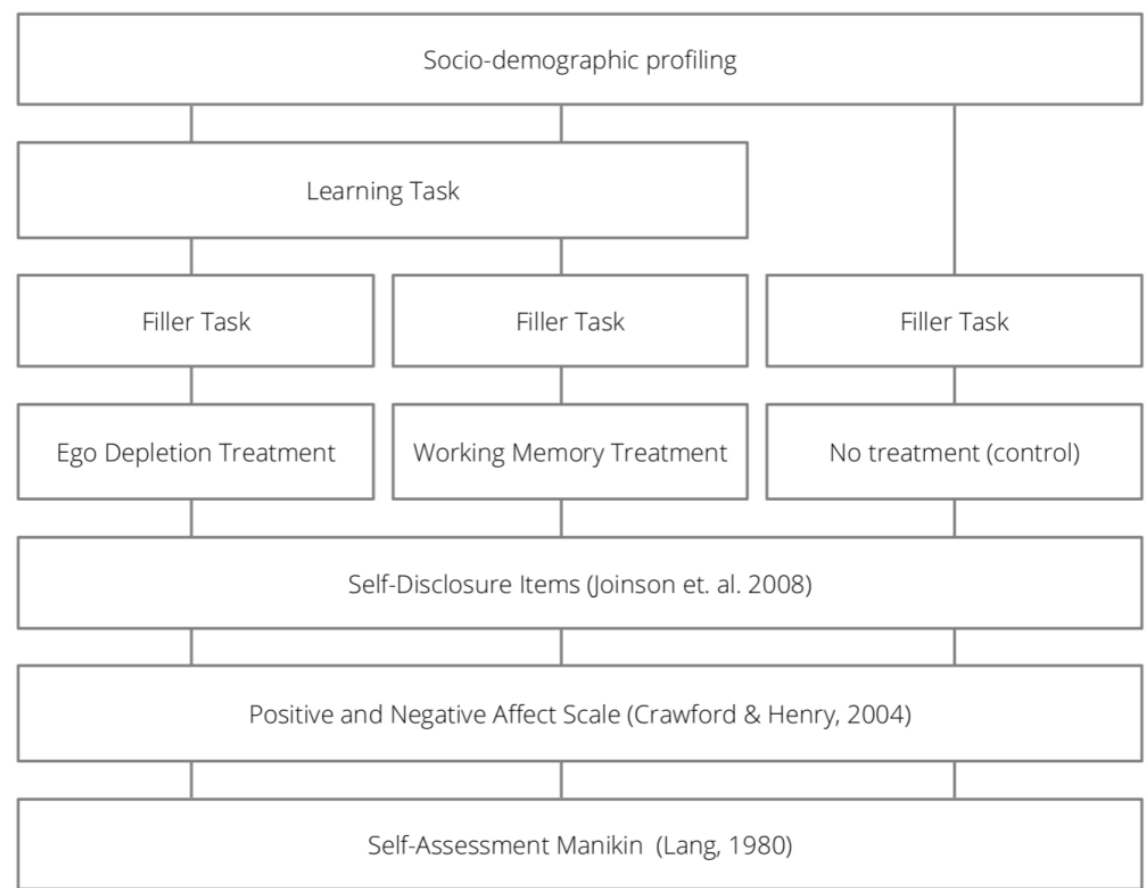


Manipulation of ego depletion. To assess the effect of attention deficit on the privacy disclosure levels, we followed an experimental procedure developed by Stroop (1935). Selective attention deficit was introduced by asking participants to repeatedly indicate the colour of a word displayed on the page under the condition that the colour of a word is different from the colour it actually names (see Appendix, figure 4). For example, if the word "green" is displayed using a red font, participants are supposed to choose the answer "red". Five colours only were used in the test: green, red, blue, brown and purple (Stroop, 1935). Each colour had an equal probability of being displayed to participants in the experiment. After completing a short trial stage with dominantly congruent settings (e.g. $80 \%$ of words with a congruent name and colour and $20 \%$ of words with incongruent colour and name), participants proceeded to the full-scale experiment and were presented with a random sequence of 80 words with congruent and incongruent names and colours. Prior research has shown that frequency of tasks and proportion of congruent and incongruent colours may moderate the amount of the generated attention deficit (Jacoby, Lindsay \& Hessels, 2003; Jacoby, McElree \& Trainham, 1999; Levin \& Tzelgov, 2014; Tzelgov, Henik \& Berger, 1992). In our experiment, a neutral (balanced) proportion of 50\% congruent and $50 \%$ incongruent colours were used.

Manipulation of cognitive load. Before being asked to self-disclose private information, we induced the cognitive load by asking participants to complete a secondary task. Following Aydinoğlu \& Krishna (2011), in this task participants were presented with a list of the names of 16 children and were asked to remember which first name came with which last name. Participants were told that, in order to make the task more realistic and difficult, they would be required to do a secondary task answer several questions about them. After participants completed the secondary task, they were asked to recall and indicate the last names of the 5 randomly picked first names. Prior research has shown that such tasks are capable inducing cognitive load (Aydinoğlu \& Krishna, 2011; Gilbert, Brian \& Morris, 1995; Spencer, Fein, Wolfe, Fong \& Duinn, 1998). 
Control condition. In the control condition, participants completed a set of socio-demographic questions followed by a filler task with unrelated questions on their shopping preferences and a 30item self-disclosure questionnaire.

\section{Results}

Previous research demonstrated effects of cognitive scarcities on individual's behaviour (Baumeister et al. 2008; Hagger et al., 2010; Samson \& Kostyszyn 2015). Results of our study demonstrate negative impact of reduced working memory as well as ego depletion on the levels of privacy disclosure. Table 2 reports the outcome of testing the marginal effects of the two treatments and several covariates, including controlling for interaction effects between emotion-related variables and experimental conditions. We use a linear model with the previously-described composite indicator of disclosure as a dependent variable. Among the independent variables we have age, education, gender (dummy), the SAM and PANAS scales indicators and the interactions effects. In this case, we are not interested in a structural model, and therefore in the overall fitness of it (consequently, the $R^{2}$ of the full model is irrelevant here) but only in the significance of the marginal effect of each treatment represented by the two independent variables.

Table 2: Effect of cognitive scarcity over information disclosure, $N=969$. 


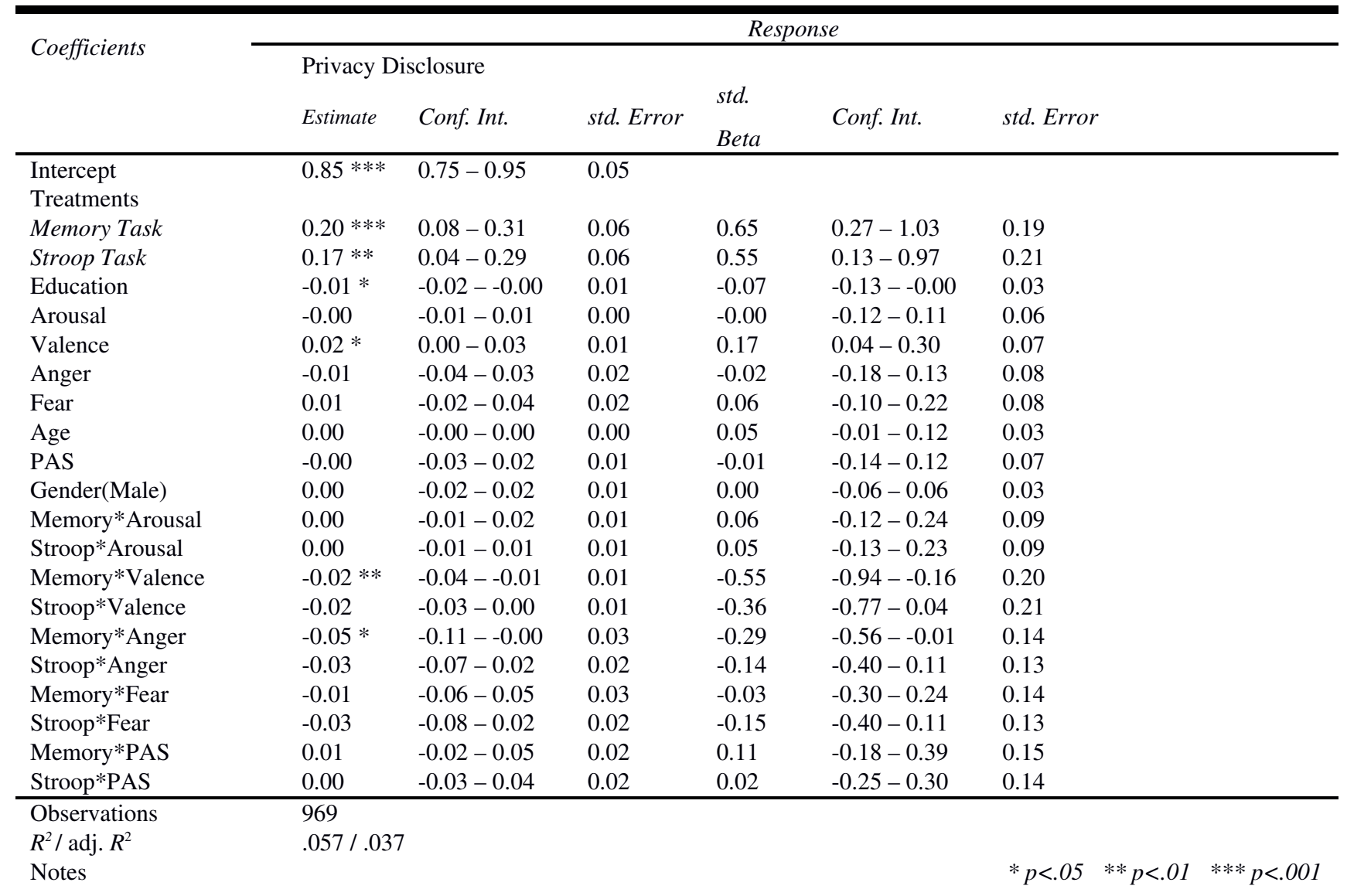


As reported in table 2, both forms of cognitive scarcity, ego depletion (Stroop task) and the cognitive load (memory task), had a significant effect in increasing the amount of information disclosure in participants after controlling for affect, both positive and negative, gender, age and education and related interaction effects. The interaction effects regard the control for emotional status, as previously discussed in section 2. Education had a significant but negligible effect in terms of reducing disclosure: the small size might be explained by the relative high education level of our sample. No age and gender effects were substantial and significant on information disclosure.

Comparing the two forms of cognitive scarcity, their effect appears to be very similar with the memory task inducing a slightly higher level of information disclosure compared to the case of ego depletion. Both cases of cognitive scarcity induce higher information disclosure. One further consideration is that our sample was very inclined to trust, probably because they recognised that an academic institution was the author of this study. Nevertheless, both instances of cognitive scarcity increased even further information disclosure.

\section{Discussion}


The large majority of previous studies about the antecedents of privacy information disclosure assume a condition of cognitive 'normality' in individuals when testing the relative importance of framing (Adjerid et al, 2015), social norms and contexts (Acquisti, John \& Lowestein, 2012, emotional states (Wang et al, 2011) and information architecture elements such as defaults. However, as highlighted by the recent scientific literature on cognitive scarcity (Mullainathan \& Shafir, 2013), conditions of cognitive depletion can greatly affect decision-making processes. We experimentally demonstrate the negative effect of two forms of cognitive scarcities, working memory and ego depletion, on privacy disclosure levels. These findings contribute to a growing body of research on the so-called "privacy paradox" issue (Acquisti et al., 2015): the presence of a paradox, and of a gap of more disclosure in people's behaviour compared to their attitudes, might be also due to the often-depleted conditions of cognitive bandwidth that people have when asked to make choices (compared to when they are asked about their attitudes towards privacy).

At the same time, this study introduces the role of cognitive scarcity related to self-regulation or ego depletion in the context of HCI research. As previously discussed, the issue of cognitive scarcity has been considered mainly in the context of cognitive load theory. However, as consider online platform that require information disclosure from users as their fundamental rational to function, for example social media, self-regulation behaviour plays an important role considering the latter as a limited commodity that restricts self-regulatory capability (Baumeister \& Heatherton, 1996; Fishbach, Friedman \& Kruglanski, 2003). In our results, it was this form of cognitive scarcity was almost as significant as the working memory one and, therefore, requires further investigation in the future. 
Regarding the limitations of our study: first, the field experiment did not allow for control over participants' circumstances of response. However, the sample size for each of the experimental conditions should compensate for that. Second, controlling for emotions was limited to self-reported scales, an unavoidable limitation in the case of a field study. However existing studies show that the scale used is consistent with physiological measures (Ordonana et al., 2009). Third, there is the need to develop a range of tests with several indicators to measure information disclosure, rather than relying on one single composite model; in particular, a combination of highly contextual (related to particular domain, such as finance, health, etc.) and more general indicators of behavioural choice. We opted for an indicator that has already been tested in terms of construct validity.

\section{Conclusions}

The influence of working memory load and ego depletion on participants' information disclosure is relevant for the design of privacy settings and are a warning against the use of informationprovision-only measures to protect individuals' data. There are two broad categories of possible sources of cognitive scarcity: one is environmental or contextual, meaning other activities that are carried out by individuals at the same time of privacy related decisions; the second source of cognitive scarcity is related to the interfaces themselves and how they present information about privacy settings, labelled as extraneous cognitive load in the cognitive load theory (Hollender, Hofmann, Deneke \& Schmitz, 2010). 
In this case, we have simulated environmental and contextual 'cognitive noise' that would normally affect users in reducing one's available cognitive resources when facing information disclosure choices online. Furthermore, we have distinguished between two types of cognitive load, based on their different nature in terms of affecting distinct cognitive process. The issue of overloaded working memory speaks directly to the topic of extraneous cognitive load in cognitive load theory. It confirms the importance of design choices that can minimise users' working memory in the context of making important decisions afterwards and can, perhaps, inform a better sequencing of such choices in an online platform. For example, privacy choices should come first, rather than last, in account settings when little prior information has to be memorised. Furthermore, an additional possibility to improve privacy-related choices is the use of heuristics. The most powerful mechanism that affects information disclosure is probably the setting of defaults. These options are pre-set courses of action that take effect if nothing is specified by the decision maker (Thaler \& Sunstein, 2008). Due to factors such as inertia and uncertainty, the default information visibility setting on social networking sites strongly affects actual information disclosure (Gross \& Acquisti, 2005).

The issue of ego depletion is more difficult to tackle because a decreased capacity of self-regulation is strictly related to one's chain of activities. It is recognised now that users/consumers tend to be affected by the licensing effect of a prior commitment to a virtuous act on subsequent choice in terms of making indulgent, less self-regulated decisions more likely (Khan \& Dhar, 2006). Again, such fact speaks in favour of default options solutions rather than relying on self-regulation of individuals about privacy once provided with the necessary contextual information, as exemplified by most online platforms. In addition, it would suggest that the revision of privacy settings at given temporal intervals might counteract decisions made when someone is affected by temporary ego depletion. Some platforms, such Google and Facebook, do ask users to revise their privacy policy every now and then: this method, implemented more systematically, could be effective in improving users' protection and awareness. 


\section{References}

Acquisti, A. (2004). Privacy in electronic commerce and the economics of immediate gratification. (2004). In Fifth ACM Conference on Electronic Commerce, New York (pp. 21-29).

Acquisti, A., Brandimarte, L. \& Loewenstein, G. (2015). Privacy and human behavior in the age of information. Science, 347(6221), 509-514.

Acquisti, A., John, L. K. \& Loewenstein, G. (2012). The impact of relative standards on the propensity to disclose. Journal of Marketing Research, 49(2), 160-174.

Acquisti, A., John, L. K. \& Loewenstein, G. (2013). What is privacy worth? The Journal of Legal Studies, 42(2), 249-274.

Acquisti, J. \& Grossklags, A. (2007, June 6). When 25 cents is too much: An experiment on willingness-to-sell and willingness-to protect personal information. In Sixth Workshop on the Economics of Information Security, Pittsburgh, PA (pp. 7-18).

Adjerid, I., Acquisti, A., Brandimarte, L. \& Loewenstein, G. (2013). Sleights of privacy: Framing, disclosures, and the limits of transparency. Paper presented at the Ninth Symposium on Usable Privacy and Security (SOUPS ’13). ACM, 2013. doi: 10.1145/2501604.2501613.

Aydinoğlu, Ni. Z. \& Krishna, A. (2011). Guiltless Gluttony: The Asymmetric Effect of Size Labels on Size Perceptions and Consumption. Journal of Consumer Research, 37(6), 1095-1112. http://doi.org/10.1086/657557

Ayres, P. \& Gog, T. van. (2009). State of the art research into Cognitive Load Theory. Computers in Human Behavior, 25(2), 253-257. https://doi.org/10.1016/j.chb.2008.12.007

Baddeley, A. (1992). Working memory: The interface between memory and cognition. Journal of Cognitive Neuroscience, 4(3), 281-288.

Bansal, G., Zahedi, F. \& Gefen, D. (2008, December 14-17). The moderating influence of privacy concern on the efficacy of privacy assurance mechanisms for building trust: A multiplecontext investigation. Paper presented at the 29th International Conference on Information Systems. Paris, France.

Barnes, S. B. (2006). A privacy paradox: Social networking in the United States. First Monday, 11(9). Retrieved from http://www.firstmonday.org/ISSUES/issue11_9/barnes/. 
Baumeister, R. F. \& Heatherton, T. F. (1996). Self-regulation failure: An overview. Psychological Inquiry, 7, 1-15. doi:10.1207/s15327965pli0701_1.

Baumeister, R. F., Sparks, E. A., Stillman, T. F. \& Vohs, K. D. (2008). Free will in consumer behavior: Self-control, ego depletion, and choice. Journal of Consumer Psychology, 18, 413.

Belanger, F., Hiller, J.S. \& Smith, W.J. (2002). Trustworthiness in electronic commerce: The role of privacy, security, and site attributes. Journal of Strategic Information Systems, 11, 245-270.

Besmer, A., Watson, J. \& Richter Lipford, H. (2010). The impact of social navigation on privacy policy configuration. Paper presented at the Sixth Symposium on Usable Privacy and Security. ACM.

Bradley M, Codispoti M, Cuthbert B, Lang P. (2001). Emotion and Motivation I: Defensive and Appetitive Reactions in Picture Processing. Emotion 1(3): 276-298.

Bradley, M. and Lang P. (1994) Measuring emotion: The self-assessment manikin and the semantic differential. Journal of Behavior Therapy and Experimental Psychiatry 25(1): 49-59.

Brandimarte, L., Acquisti, A. \& Loewenstein, G. (2013). Misplaced confidences: Privacy and the control paradox. Social Psychological and Personality Science, 4(3), 340-347.

Calvo M, Lang P. (2004) Gaze Patterns When Looking at Emotional Pictures: Motivationally Biased Attention. Motivation and Emotion 28(3): 221-243.

Cialdini, R. B. (2008). Influence: Science and practice (5th ed.). Boston: Pearson.

Contena, B., Loscalzo, Y. \& Taddei, S. (2015). Surfing on social network sites: A comprehensive instrument to evaluate online self-disclosure and related attitudes. Computers in Human Behavior, 49(C), 30-37.

Cranor, L. F., Reagle, J. \& Ackerman, M. S. (1999). Beyond concern: Understanding net users' attitudes about online privacy. Technical report, TR 99.4.3, AT\&T Labs - Research. Retrieved from research.att.com/resources/trs/TRs/99/99.4/99.4.3/report.htm

Crawford J, Henry J. (2004). The Positive and Negative Affect Schedule (PANAS): Construct validity, measurement properties and normative data in a large non-clinical sample. British Journal of Clinical Psychology, 43: 245-265.

Damasio, A. R. (1994). Descartes' error: Emotion, reason, and the human brain. New York: Putnam. 
Fishbach, A. \& Labroo, A. A. (2007). Be better or be merry: How mood affects self-control. Journal of Personality and Social Psychology, 93, 158-173. doi:10.1037/0022-3514.93.2.158

Fishbach, A. Friedman, R. S., \& Kruglanski, A. W. (2003). Leading us not unto temptation: Momentary allurements elicit overriding goal activation. Journal of Personality and Social Psychology, 84, 296-309.

Folkman, S. \& Moskowitz, J. T. (2000). Positive affect and the other side of coping. American Psychologist, 55, 647-654. doi:10.1037/0003-066X.55.6.647

Gilbert, D. T., Brian, R. \& Morris, K. A. (1995). When comparisons arise. Journal of Personality and Social Psychology, 69(2), 227-236. http://doi.org/10.1037/0022-3514.69.2.227

Hagger, M. S., Wood, C., Stiff, C. \& Chatzisarantis, N. L. D. (2010). Ego depletion and the strength model of self-control: A meta-analysis. Psychological Bulletin, 136(4), 495-525.

Hollender, N., Hofmann, C., Deneke, M. \& Schmitz, B. (2010). Integrating cognitive load theory and concepts of human-computer interaction. Computers in Human Behavior, 26(6), 12781288. https://doi.org/10.1016/j.chb.2010.05.031

Hoofnagle, C. J. \& Urban, J. M. (2014). Alan Westin's Privacy Homo Economicus. Wake Forest Law Review, 47, 261-321.

Jacoby, L. L., Lindsay, D. S. \& Hessels, S. (2003). Item-specific control of automatic processes: stroop process dissociations. Psychonomic Bulletin \& Review, 10(3), 638-644.

Jacoby, L. L., McElree, B. \& Trainham, T. N. (1999). Automatic influences as accessibility bias in memory and stroop tasks. Attention and Performance, 17. Retrieved from https://nyu.pure.elsevier.com/en/publications/automatic-influences-as-accessibility-bias-inmemory-and-stroop-t

John, L. K., Acquisti, A. \& Loewenstein, G. (2011). Strangers on a plane: Context-dependent willingness to divulge sensitive information. Journal of Consumer Research, 37, 858-873.

Joinson, A. N. \& Reips, U.-D. (2008). Measuring self-disclosure online: Blurring and non-response to sensitive items in web-based surveys. Computers in Human Behavior, 24(5), 2158-2171.

Kahn, U and Dhar, R. (2006) Licensing effect in consumer choice. Journal of Marketing Research 153: 259-266. 
Kehr, F., Kowatsch, T., Wentzel, D., \& Fleisch, E. (2015). Blissfully ignorant: the effects of general privacy concerns, general institutional trust, and affect in the privacy calculus. Information Systems Journal, 25(6), 607-635. https://doi.org/10.1111/isj.12062

Knijnenburg, B. P. \& Kobsa, A. (2013). Making decisions about privacy: Information disclosure in context-aware recommender systems. ACM Transactions on Interactive Intelligent Systems, 3(3), 20:1-20:23.

Lerner, J. S., \& Keltner, D. (2001). Fear, anger, and risk. Journal of Personality and Social Psychology, 81(1), 146-159. https://doi.org/10.1037/0022-3514.81.1.146

Levin, Y. \& Tzelgov, J. (2014). Conflict components of the Stroop effect and their "control". Frontiers in Psychology, 5. http://doi.org/10.3389/fpsyg.2014.00463

Li, H., Sarathy, R., \& Xu, H. (2011). The role of affect and cognition on online consumers' decision to disclose personal information to unfamiliar online vendors. Decision Support Systems, 51(3), 434-445. https://doi.org/10.1016/j.dss.2011.01.017

Loewenstein, G., \& Lerner, J. S. (2003). The role of affect in decision making. In R. J. Davidson, K. R. Scherer, \& H. H. Goldsmith (Eds.), Handbook of affective sciences (pp. 619-642). New York, NY, US: Oxford University Press.

Loewenstein, G., O’Donoghue, T. \& Rabin, M. (2003). Projection bias in predicting future utility. Quarterly Journal of Economics, 118(4), 1209-1248.

Lowry, P. B., Wilson, D. W. \& Haig W. L. (2014). A picture is worth a thousand words: Source credibility theory applied to logo and website design for heightened credibility and consumer trust. International Journal of Human-Computer Interaction, 30(1), 63-93.

MacLeod, C., \& Mathews, A. (1988). Anxiety and the allocation of attention to threat. The Quarterly Journal of Experimental Psychology Section A, 40(4), 653-670. https://doi.org/10.1080/14640748808402292

Malheiros, M., Preibusch, S. \& Sasse. M. (2013). 'Fairly truthful': The impact of perceived effort, fairness, relevance, and sensitivity on personal data disclosure. In Proceedings of the 6th International Conference on Trust \& Trustworthy Computing (pp. 250-266).

Mayer, J. D. \& Gaschke, Y. N. (1988). The experience and meta-experience of mood. Journal of Personality and Social Psychology, 55, 102-111. doi:10.1037/0022-3514.55.1.102 
Mullainathan, S. \& Shafir, E. (2013). Scarcity: Why Having Too Little Means So Much. New York: Time Books, Henry Holt \& Company.

Norberg, P. A., Horne, D. R. \& Horne, D. A. (2007) The privacy paradox: Personal information disclosure intentions versus behaviors. Journal of Consumer Affairs, 41(1), 100-126.

Olivero, N. \& Lunt, P. (2004). Privacy versus willingness to disclose in ecommerce exchanges: The effect of risk awareness on the relative role of trust and control. Journal of Economic Psychology, 25(2), 243-262.

Ordoñana J, González-Javier F, Espín-López L, Gómez-Amor J. (2009). Self-Report and Psychophysiological Responses to Fear Appeals. Human Communication Research 35: 195220.

Park, Y. J., Campbell, S. \& Kwak, N. (2012). Affect, cognition and reward: Predictors of privacy protection online. Computers in Human Behavior, 28(3), 1019-1027.

Park, Y. J., Campbell, S. W., \& Kwak, N. (2012). Affect, cognition and reward: Predictors of privacy protection online. Computers in Human Behavior, 28(3), 1019-1027. https://doi.org/10.1016/j.chb.2012.01.004

Patil, S., Page, X. \& Kobsa, A. (2011). With a little help from my friends: Can social navigation inform interpersonal privacy preferences? In Proceedings of the ACM Conference on Computer Supported Cooperative Work, New York (pp. 391-394).

Rifon, N. J., LaRose, R. \& Choi, S. M. (2005). Your privacy is sealed: Effects of Web privacy seals on trust and personal disclosures. Journal of Consumer Affairs, 39(2), 339-362.

Rose, E., (2005). "Data Users versus Data Subjects: Are Consumers Willing to Pay for Property Rights to Personal Information?” Proceedings of the 38th Hawaii International Conference on System Sciences.

Samson, A. \& Voyer, B. (2012). Two minds, three ways: Dual system and process models in consumer psychology. Academy of Marketing Science Review, 2, 48-71.

Samson, A. \& Voyer, B. (2014). Emergency purchasing situations: Implications for consumer decision making. Journal of Economic Psychology, 44, 21-33.

Samson, K. \& Kostyszyn, P. (2015). Effects of Cognitive Load on Trusting Behavior - An Experiment Using the Trust Game. PLOS ONE, 10(5), e0127680. 
Schulz, J. F., Fischbacher, U., Thöni, C., \& Utikal, V. (2014). Affect and fairness: Dictator games under cognitive load. Journal of Economic Psychology, 41, 77-87. https://doi.org/10.1016/j.joep.2012.08.007

Smith, H. J. Dinev, T. \& Xu, H. (2011). Information privacy research: An interdisciplinary review. MIS Quarterly, 35(4), 989-1015.

Spencer, S. J., Fein, S., Wolfe, C. T., Fong, C. \& Duinn, M. A. (1998). Automatic Activation of Stereotypes: The Role of Self-Image Threat. Personality and Social Psychology Bulletin, 24(11), 1139-1152. http://doi.org/10.1177/01461672982411001

Spiekermann, S., Grossklags, J. \& Berendt, B. (2001). E-Privacy in 2nd generation e-commerce: Privacy preferences versus actual behavior. In Third ACM Conference on Electronic Commerce, Tampa, FL (pp. 38-47).

Stroop, J. R. (1935). Studies of interference in serial verbal reactions. Journal of Experimental Psychology, 18(6), 643-662.

Stutzman, F., Gross, R. \& Acquisti, A. (2013). Silent listeners: The evolution of privacy and disclosure on Facebook. Journal of Privacy and Confidentiality, 4(2), 2.

Tsai, J. Y., Egelman, S., Cranor, L. \& Acquisti, A. (2011). The Effect of Online Privacy Information on Purchasing Behavior: An Experimental Study. Information Systems Research, 22(2), 254-268. http://doi.org/10.1287/isre.1090.0260

Tufecki, Z. (2008). Can you see me now? Audience and disclosure regulation in online social network sites. Bulletin of Science, Technology and Society, 28(20), 20-36.

Tversky, A. \& Kahneman, D. (1974). The framing of decisions and the psychology of choice. Science, 211, 453-458.

Tzelgov, J., Henik, A. \& Berger, J. (1992). Controlling Stroop effects by manipulating expectations for color words. Memory \& Cognition, 20(6), 727-735.

Wang, Y., Komanduri, S., Leon, P. G., Norcie, G., Acquisti, A. \& Cranor, L. F. (2011). I regretted the minute I pressed share: A qualitative study of regrets on Facebook. Paper presented at the Symposium on Usable Privacy and Security (SOUPS).

Westin, A. \& Harris Louis \& Associates. (1991). Harris-Equifax Consumer Privacy Survey. Equifax Inc.

Westin, A. (1998). Ecommerce and privacy: What net users want. PricewaterhouseCoopers. 
$\mathrm{Xu}, \mathrm{H}$. (2007). The effects of self-construal and perceived control on privacy concerns. In Proceedings of the 28th International Conference on Information Systems, Montréal, Canada, December 9-12.

Xu, H., Teo, H. H., Tan, B. C. Y. \& Agarwal, R. (2010). The role of push-pull technology in privacy calculus: The case of location-based services. Journal of Management Information Systems, 26(3), 137-176.

Young, A. L. \& Quan-Haase, A. (2013). Privacy protection strategies on Facebook: The Internet privacy paradox revisited. Information, Communication \& Society 16(4), 479-500. 